\title{
Stepping down from the ivory tower: Inviting the patient for mutual responsibility
}

\author{
Ari A. Mennander, $\mathrm{MD}, \mathrm{PhD}$
}

From Tampere University Heart Hospital and Tampere University, Tampere, Finland.

Disclosures: Author has nothing to disclose with regard to commercial support.

Received for publication April 5, 2018; accepted for publication April 9, 2018; available ahead of print May 4, 2018

Address for reprints: Ari A. Mennander, MD, PhD, Tampere University Heart Hospital, SDSKIR, PL 2000, Tampere, Finland (E-mail: ari.mennander@sydansairaala.fi).

J Thorac Cardiovasc Surg 2018;156:1496-7

$0022-5223 / \$ 36.00$

Copyright (c) 2018 by The American Association for Thoracic Surgery

https://doi.org/10.1016/j.jtcvs.2018.04.038

How delightful it would be to practice straightforward surgery during a complex clinical scenario of mitral valve endocarditis. The bad tissue is resected, and mitral valve repair or replacement is performed. The sooner the surgery is performed, the better the results, especially with Staphylococcus aureus, which accounts for almost a third of the microorganisms during endocarditis. ${ }^{1}$ The basic rule includes resecting all infective focus and reconstructing the heart accordingly.

Back to reality. Many rules become controversial, and many seemingly dull clichés may apply; one has to "see the forest from the trees" and "take the patient as a whole." Clinical details, such as history of embolism, the size of vegetation, and the presence of heart failure, cerebral stroke, sepsis, and microorganisms, interfere with the choice of treatment. Deciding between medical treatment and surgery, the timing of surgery, the choice of prosthesis, all determine the fate of the patient. ${ }^{2}$ In short, one ought to discuss the case before acting; are all safety precautions, consulting measures, and clinical experience provided adequately?

The article in this issue of the Journal by Nappi and colleagues ${ }^{3}$ describes the surgical steps during the operational decision making. Nappi and colleagues ${ }^{3}$ share their valuable experience in treating patients with mitral valve endocarditis while referring to previous studies. Figures and algorithms are presented to pinpoint the main message. A step-by-step procedure is advised for the evaluation of the disease, and a surgical solution is offered accordingly. Importantly, the article adds to what modern surgery encompasses at its best: a multidisciplinary team works based on a patient-centered approach. Evidently, this review will be helpful to delineate the need for early surgery and the effectiveness of supportive medicine and antibiotics.

The fascination of medicine is based on allowing discussion of which mitral endocarditis is far from spared; does mitral valve repair enhance recovery as opposed to mitral

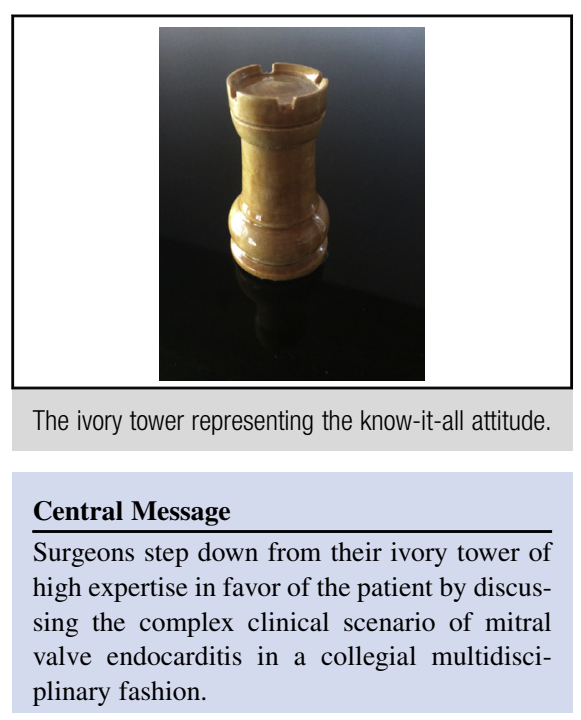

See Article page 1486. valve replacement? Are we convinced that recurrent endocarditis is related to either mechanical or biologic prosthesis? The implantation of papillary muscles or addition of a supportive mitral ring while using a homograft may add to the complexity of the reconstructive surgery. ${ }^{3} \mathrm{Me}$ chanical valves and anticoagulation may well be tolerated by some. New anticoagulation protocols are currently under rigorous investigation. ${ }^{4}$ Even possible pregnancy may not anymore be an absolute contraindication for receiving a mechanical valve, ${ }^{5}$ and quality of life may be difficult to argue objectively after surgery for endocarditis. ${ }^{6}$ Today, it seems absurd to discuss mini-invasiveness of surgery for endocarditis, but in the future, this may become the reality. Does the elderly patient favor a limited approach in the hope of an instant recovery while accepting the risk of recurrent infection instead of undergoing a demolition surgical operation together with a homograft, possibly leading to an early stenotic valvular disease? It definitely matters for decision making how competent the surgeons prove to be technically, but some patients may still choose differently from what experts recommend. After being shown all options openly, the enlightened patient may decide individually, sometimes even against our own ethics and experience. The multidisciplinary, patientcentered approach to decision making offers shared responsibility. 


\section{References}

1. Desch S, Freund A, de Waha S, Eitel L, Lurz P, Stiermaier T, et al. Outcome in patients with left-sided native-valve infective endocarditis and isolated large vegetation. Clin Cardiol. 2014;37:626-33.

2. Marushchak O, Cole H, Hiebert B, Lo E, Keynan Y, Tam J, et al. Analysis of shortand long-term outcomes of patients with surgically treated left-sided infective endocarditis: a 5-year longitudinal follow-up study. Semin Thorac Cardiovasc Surg. 2017;29:311-20

3. Nappi F, Spadaccio C, Dreyyfus J, Attias D, Acar C, Bando K. Mitral endocarditis: a new management framework. J Thorac Cardiovasc Surg. 2018; 156:1486-95.e4
4. Yinon Y, Siu SC, Warshafsky C, Maxwell C, McLeod A, Colman JM, et al. Use of low molecular weight heparin in pregnant women with mechanical heart valves. Am J Cardiol. 2009; 104:1259-63.

5. De Santo LS, Romano G, Della Corte A, D’Oria V, Nappi G, Giordano S, et al. Mechanical aortic valve replacement in young women planning on pregnancy: maternal and fetal outcomes under low oral anticoagulation, a pilot observational study on a comprehensive pre-operative counseling protocol. J Am Coll Cardiol. 2012;59:1110-5.

6. Perrotta S, Aljassim O, Jeppson A, Bech-Hanssen O, Svensson G. Survival and quality of life after aortic root replacement with homografts in acute endocarditis. Ann Thorac Surg. 2010;90:1862-8. 